\title{
The nouns in English
}

\author{
Liu Juan ${ }^{1, a}$, Zhou Wen ${ }^{1, b}$ \\ ${ }^{1}$ International College of Yunnan Agricultural University, China-ASEAN Education and Training \\ Center, Kunming, Yunnan, China \\ a454965156@qq.com, ${ }^{\mathrm{b}} 706931894 @ q q . c o m$
}

Keywords: Basic Grammatical Categories, Fundamental Of Grammar Learning, Nouns Countable And Uncountable Nouns Chinese Elementary Learners

\begin{abstract}
This paper explains how to teach nouns to the elementary learners in Chinese middle schools, including the basic teaching methods and the exercise. The different way to learn grammar also be demonstrated in the paper.
\end{abstract}

\section{Introduction}

Nouns defined as one of the basic grammatical categories and used as denoting a person, thing, place, event, idea, etc. Parrott (2000) points out that nouns deliver a substantial proportion of the information in most texts and served as subject, object and the complement of a verb. For these reasons, learning how to use nouns is the fundamental of grammar learning, because nouns can help people to express the main idea of discourse. In listening, speaking, reading and writing English, if people do notknow the meanings of nouns in sentences, it will be difficult to comprehend the exact meanings that people want to express. For instance, 'I will go to bakery and buy strawberry cakes for my sisters.' In this sentence, even though learners know the meanings of the verbs, pronouns, and preposition, they still cannot catch the accurate meaning of the sentence. In this essay, firstly, I will focus on teaching proper nouns and common nouns for elementary learners in Chinese middle schools, including the form, meaning and use. And then the emphasis will be placed on discussing the problem they might have. After that, this essay will discuss how to teach countable and uncountable nouns, which could be the most problematic aspect of nouns that Chinese elementary learners in middle schools might encounter.

\section{Proper Nouns and Common Nouns}

In terms of proper nouns, there are two obvious features distinguished from common nouns, one is that proper nouns begin with capital letters no matter where it is in a sentence. The other is that proper nouns describe unique items. Words which begin with capital letters and are not at the beginning of sentences are often the names of people, places (towns, countries, etc.) or institutions. These are also called 'proper' nouns (Parrott, 2000:9). Proper nouns contrast with common nouns, which denote classes of entity (Leech, 1992:98). For instance, the name of people: Andrews, Julis. The name of place: Europe, Asia, Loch Ness, Washington Square. The name of month and festival: May, New Year's Eve. The name of newspaper and magazines: Time, New Statesman, etc. In contrast, common nouns are the least complicated to learn in English as a category of nouns. They are general words to name a class of entities. 


\begin{tabular}{|c|c|}
\hline Common nouns & Proper nouns \\
\hline boy & Allen and Rose \\
\hline flower & United Kingdom \\
\hline school & Red cross \\
\hline book & Christmas \\
\hline father & Parliament \\
\hline waiter & Yale University \\
\hline
\end{tabular}

Proper nouns refers to a unique entity and most of them have no plural forms, and do not normally have articles or other determiners. Sloat (1969) states that free selection of determiners and numbers obviously simplifies restrictions of the use of proper nouns. Leech (1992) points out that proper nouns do not vary for number: most proper nouns are singular, and a few are plural. For instance, names of mountain ranges such as Rockies are plural, most of the unique places, people's names, the name of counties such as the Great Wall, Kennedy, America are singular.

For Chinese learners, proper nouns and common nouns are easier than other class of nouns to distinguish and memorize. Because recognition and meaning of general and unique entities in English is the same with that in Chinese, and proper nouns and common nouns are used in daily life frequently and widely. So Chinese learners less have difficulties in comprehending proper and common nouns. However, problems do exist in the learning of proper nouns for the elementary students in middle schools. That is proper nouns can be used as count nouns in certain cases. For example,

Have you seen my Gone With Wind? ( my cope of a novel )

There were three Janes in our class. (three single instances of the same name-three girls called Jane)

\section{Countable and Uncountable Nouns}

Nouns can be divided into two major grammatical types, count nouns and non-count nouns. (Carter, R and McCarthy, M, 2006:335). Carter and McCarthy state that countable nouns are the largest group of nouns, they denote entities which are treated as units and refer to objects, people, abstract entities, etc. For example, ideas, bottles, cups, leaves, basketballs, etc.

Countable nouns have a singular and a plural form (Parrott, 2000:10). In terms of singular form, the indefinite article a/an can be used with count nouns in the singular (Carter, R and McCarthy, M, 2006: 336). For instance, she want to buy a bag, a boy is swimming, she is eating an apple. What should be highlighted is that singular count nouns must come with a determiner. For example:

Bird is flying. $\times$

A bird is flying. $\sqrt{ }$

She is watching movie. $x$

She is watching the movie. $\sqrt{ }$

When it comes to the plural form of countable nouns, determiners can be used to indicate number or quantity of nouns. Determiners come in front position in noun phrases, before adjectives and noun modifiers. (Carter, R and McCarthy, M, 2006: 353). For example,

What is your name?

Where are the house?

I am her sister.

We have little water.

Almost all books are bought by that man. 


\section{uncountable nouns}

Carter, R and McCarthy, M (2006) points out that uncountable nouns show no contrast in number between singular and plural, they typically refer to things such as materials and liquids, states of mind, conditions, topics, processed and substances. And uncountable nouns are divided into singular uncountable nouns and plural uncountable nouns.

singular uncountable nouns

Singular uncountable nouns are not used with the indefinite article a/an or in the plural (Carter, R and McCarthy, M, 2006:339). For example,

My sister prefers listen to a music. $\times$

My sister prefers listen to music. $\sqrt{ }$

Could you give me some informations? $\times$

Could you give me some information? $\sqrt{ }$

Here is some typical singular uncountable nouns for upper-intermediate student in Chinese high schools:

\begin{tabular}{|l|l|l|l|l|}
\hline furniture & sand & water & tea & traffic \\
\hline information & advice & juice & oil & homework \\
\hline luggage & work & milk & rice & cash \\
\hline weather & help & coffee & salt & hair \\
\hline knowledge & money & fruit & air & news \\
\hline violence & luck & jam & cotton & harm \\
\hline progress & soap & sugar & smoke & chaos \\
\hline
\end{tabular}

plural uncountable nouns

some uncountable nouns always appear in the plural form, for example, bipartite nouns. Bipartite nouns include garments with two legs worn around the waist (e.g. jeans), instruments worn over both eyes or both ears related to sight and hearing (e.g. headphones) and tools consisting of two similar parts on a pivot (e.g. scissors) (Carter, R and McCarthy, M, 2006:342). For example,

Bipartite nouns

\begin{tabular}{|l|l|l|}
\hline tools & garments & instruments \\
\hline scissors & jeans & glassed \\
\hline tongs & pants & goggles \\
\hline shears & shorts & headphones \\
\hline tweezers & trousers & spectacles \\
\hline pliers & underpants & binoculars \\
\hline pincers & pyjamas & \\
\hline & briefs & \\
\hline & jodhpurs & \\
\hline & knickers & \\
\hline
\end{tabular}

Besides these bipartite nouns, some uncountable nouns that are terminated with letter "s" are always grammatically plural. For example, I understand congratulationsare due on the new job, by the way. The outskirts of the city are rather drab and uninteresting. The proceeds of the concert are all going to charity (Carter, R and McCarthy, M, 2006: 324).

For Chinese students in middle schools, they may be surprised that some nouns, such as money, hair, news, are treated as uncountable nouns in English, because in Chinese, money, hair, news, soap, information can be counted. At the beginning of learning uncountable nouns, students could be confused and do not know how to distinguish countable nouns from uncountable nouns. Learner 
may be misled by their own language, e.g. the equivalent of an uncountable word in English such as money may be countable, or something may simply seem logical to them (e.g. Information 'ought' to be countable) (Parrot, 2000:19). For solving this problem, teachers can explain the detailed definition from Parrott (2000) to students: nouns which describe liquids, materials, substances and abstract qualities are characteristically uncountable. Meanwhile, giving students lots of typical uncountable nouns used in the daily life and asking them to memorize them could be the appropriate direct teaching methods.

Another difficulty that Chinese students might have is that some nouns could be uncountable nouns as well as countable nouns. They have two different meanings when they are countable and uncountable. For example, work and works, experience and experiences, water and waters, etc. Carter, R and McCarthy, M (2006) points out that some uncountable nouns are often referred to as 'dual class' nouns, because of their ability to operate in two different ways:

Do you drink coffee? (general, uncountable use)

I'd like two coffees. (particular, two cups of coffee)

Do you like some cake? (general, uncountable use, a piece of a big cake)

Do you want a cake with your coffee? (an individual item)

Experience must count for something in such situations. (a person's accumulated life experience or work experience)

It was a great experience. (an individual event as lived through by someone)

She's had some very odd experiences, I must say. (odd events have happened to her).

the use of nouns

When it comes to learning of nouns in Chinese middle schools, they need to learn three mainly use of nouns, 1): subject of the sentence. The nominative is the 'subject-case,' it main function being to mark the subject of a sentence (Sweet, H. P, 1891:49). For example, a watermelon is much sweeter than a lemon. William wants to become a teacher. 2): direct object of the sentence. The accusative or 'direct object case' serves to complete the meaning of a transitive verb (Sweet, $\mathrm{H}$. P, 1891:50). For example, the man beat the boy. The man saw the boy, boy is in the accusative relation, being regarded as the direct object of the actions expressed by beat and saw (Sweet, H. P, 1891:50). 3) predicative of the sentence. For example, my mother is a judge. His good friends are authors.

When teaching these nouns for Chinese students, what teaching methods should be used is deductive approach, not an inductive approach. That means teaching the form, meaning and use of varied nouns firstly, which are the grammar rules of nouns. Then, ask students to memorize them. Second and foreign language teaching, on the other hand, is primarily concerned with descriptive rules, that is, with generalisations about what speakers of the language actually do say rather than with what they should do (Thornbury, 1999:11). Thornbury (1999) gives a example for directly explaining this methods: You do not normally use the with proper nouns referring to people. After explaining rules and demonstrating examples, teachers could ask students spend more time in comprehending the grammatical rules and doing practice. A deductive approach starts with the presentation of a rule and is followed by examples in which the rule is applied (Thornbury, 1999:29). Thornbury (1999) states that deductive approach gets straight to the point and allow more time for practice and application.

For Chinese students in middle schools, in the long-term learning of common nouns, they may feel that learning nouns is the job not joy. To address this problem, there could be two main approaches for teachers, 1): while teaching common nouns, give students the western cultural background or Latin root to inspire them and stimulate their interest. That could need more time for teachers to prepare, but it is worth doing. For example, the words wedding and church, teachers tell 
students how the traditional western weddings ceremony is held in churches. Through the understanding of western culture, comprehend and memorization become more intuitive and expressive. 2 ): Teaching grammar through texts could also be the effective approaches for teachers. Nouns have different meanings in different contexts. Thornbury (1999) sets some examples for proving this:

What does this word mean

Can I have a word with you

I give you my word

Word has it that they are getting married

The above words 'word' look the same, but all have different meanings. Language is context-sensitive. This means that, in the absence of context, it is very difficult to recover the intended meaning of a single word (Thornbury, 1999:69). According to this rule, teaching nouns in the text with the context is very important.

\section{Conclusion}

Proper nouns and common nouns, countable nouns and uncountable nouns are the two main class of nouns learned by elementary learners in Chinese middle schools. Harmer (1987) states that English grammar is difficult for students due to the differences lies between English grammar and the exceptions to grammar rules. For example, some nouns cannot be made plural at all, e.g. Furniture, air, sugar. We don't say, I like those two furniture (Harmer, 1987:14). So this essay demonstrates the form, meaning and use of these nouns as well as discussing the problems that learners might have with this area. At the end of this essay, some pedagogical principles are discussed for the effective teaching of nouns.

\section{References}

[1] Carter, Ronald and McCarthy, M Cambridge grammar of English: a comprehensive guide: spoken and written English grammar and usage. Cambridge: Cambridge University Press,2006.

[2] Harmer, J. Teaching and Learning Grammar, Harlow: Longman.1987

[3] Leech, G. Introducing English Grammar, London: Penguin.1992

[4] Parrott, MGrammar for English Language Teachers, Cambridge: Cambridge University Press.2000

[5] Sloat, C.Proper Nouns in English, Language, vol. 45, 1, pp.26-30, 1969.

[6] Sweet, P. H. English Grammar. London: Oxford University Press, 1891. 